\title{
Individual variations of daily activity patterns in radiotracked European hares during winter
}

\author{
Dominique PÉPIN and Bruno CARGNELUTTI
}

Pépin D. and Cargnelutti B. 1994. Individual variations of daily activity patterns in radiotracked European hares during winter. Acta theriol. 39: 399-409.

Daily movements during winter of 2 adult male (Nos 1 and 3 ) and 2 adult female (Nos 2 and 4) radiotracking hares Lepus europaeus Pallas, 1778 were estimated from simultaneous bearings using a $50 \times 50 \mathrm{~m}$ grid. As deduced every $4 \mathrm{~h}$ both from the average rate of recorded changes of squares on the grid, and from the average distance travelled, we found that the hares had a typically nocturnal locomotor activity pattern. However, when comparing individual data, we found that significant variations occurred from 12.00 to 15.59 , and between 00.00 and 07.59 . We also estimated that the average daily activity of the hares started near sunset (mean $=23$ min after sunset, range $\pm 110 \mathrm{~min}$ ), and ended near sunrise (mean $=14$ min before sunrise, range \pm 60 $\mathrm{min}$ ), male No 1 usually spending more time in activity than the 3 other specimens. Finally, we assessed the differences in nocturnal distance travelled between individuals (Nos 2, 3, and 4) for a given period (during week 6 , mean $=3.91 \mathrm{~km}$, range 6.02-2.62), and also during several nights (during weeks $6,8,10$ and 12) for male No 3 . We concluded that some inter- and intra-individual variations of activity patterns occurred on various time scales (day-to-day or during a given night), such differences probably contributing to confuse predators.

Institut National de la Recherche Agronomique, Institut de Recherche sur les Grands Mammiferes, BP 27, 31326 Castanet-Tolosan cedex, France

Key words: Lepus europaeus, activity pattern, individual variation, France

\section{Introduction}

In order to consolidate the notion of the specificity of the circadian activity pattern influenced by endogenous components, individual differences in behaviour have often been ignored or assumed to be mere "noise" (see review in Nielsen 1984). However, as pointed out by Aschoff (1966), even if the environmental conditions do not actually produce the basic pattern, they can suppress or accentuate parts of it. And, as most natural environments vary spatially and temporally, and animals differ among themselves, such individual differences probably represent an adaptative flexibility of considerable biological importance (Kucera 1981, Slater 1981, McNamara and Houston 1986, Łomnicki 1988).

The monitoring of animal movements, permitted by the use of radiotracking systems since the early 1960s (Cochran and Lord 1963, Cochran et al. 1965), 
provided useful data for the investigation of the behaviour of animals either living in closed environments or having nocturnal habits without the necessity to observe them. Concerning lagomorph species, Mech et al. (1966) used this new technology, and broke new ground concerning the variation in length of the circadian cycle among individuals and from day to day by monitoring four wild cottontail rabbits Sylvilagis floridanus and five snowshoe hares Lepus americanus. They found that there was a wide individual variation among male cottontail rabbits, but not among female cottontail or among snowshoe hares. Consequently, they pointed out that pooling data from several animals and many days may somewhat obscure possible relationships between factors.

From that pioneering work, a review of the literature related to this fundamental aspect of the biology of lagomorphs showed, however, that little is known because only few investigators have provided satisfactory information on individual movements. Rongstad and Tester (1971) used the same radiotracking system to study the behaviour of four young snowshoe hares and the activities of a female during the time the young were being nursed, and indicated that the female was with her young only once each day for only 5 to 10 minutes, and that this time was remarkably constant from day to day. Anderson and Pelton (1976) reported eighteen telemetric observations for which the onset of evening activities of 12 radiocollared cottontail rabbits was ascertained, and found that they begin activities in winter subsequent to sunset. By pooling data recorded during weeks 2-5 and weeks $25-28$ by means of a system for automatic activity recording, Cederlund and Lemnell (1980) provided a picture of the daily pattern of a free-living male mountain hare Lepus timidus: there was a close relationship between sunset and onset of activity and sunrise and cessation of activity in winter, while during the summer's short nights this nocturnal behaviour was not as pronounced [additional data on the diurnal and seasonal activity pattern of 9 mountain hares were provided by Lemnell and Lindölf (1981)]. Similar global conclusions were also reported by Figala et al. (1984) from remote sensing data of a male snowshoe hare monitored over 26 months: nevertheless, a detailed examination of the November daily activity pattern given as an example in this paper clearly showed that important day-to-day changes in the timing of activity were recorded, but not discussed by the authors.

Data about the variation of individual activity patterns of the European hare Lepus europaeus Pallas, 1778 recorded by means of a radiotracking technique being unpublished until now, the aim of this paper is to give some information obtained by monitoring free-ranging animals during winter 1982. The present investigation of two males and two females specifically asked the following questions: (1) Are there significant inter-individual variations in the average daily activity pattern of hares as estimated from simultaneous bearings using a $50 \times$ $50 \mathrm{~m}$ grid? (2) Is the daily activity of hares related to sunset and sunrise? (3) Does the locomotor activity of hares change among individuals for a given period, or during several nights for the same animal? 


\section{Study area}

The study was carried out in the Faget area covering 1000 ha which lies in south-western France about $35 \mathrm{~km}$ north-east of the city of Toulouse $\left(43^{\circ} 37^{\prime} \mathrm{N}, 1^{\circ} 27^{\prime} \mathrm{E}\right)$. Within the study area, the elevation ranged between 170 and $270 \mathrm{~m}$. In this rolling country, the landscape mosaic is typified by wooded or fallow land ( $14 \%$ of the area), and by the rather small size of the fields ( 2 ha on average). It is devoted to mixed crop-livestock farming (maize, sorghum, winter wheat, green fodder). A more detailed description of the study area is given by Ricci (1983).

\section{Materials and methods}

\section{Management of the hare population}

Because of very heavy hunting pressure, and in spite introductions of hares, the annual hunting bag only concerns less than one individual per 10 ha (Ricci 1983, Pépin and Cargnelutti 1985). In order to protect the species, about $18 \%$ of the total area of the Faget zone, in one block, is restricted for hunting. Using total-and-strip census methods (Pépin and Birkan 1981) at the end of the winters of 1980 and 1981, it was estimated that the density of resident hares within the reserve was about three times as high as in the remainder (4.4 individuals per 100 ha vs 1.5 ) so that $40 \%$ of the total number of hares lived in the reserve (Ricci 1983).

\section{Capture and radiotracking techniques}

Using nets and beaters, a capture campaign was organized within the reserve and 2 adult males (No 1 and No 3) and 2 non-pregnant adult females (No 2 and No 4) were caught.

They were equipped with SB $21 \mathrm{~V}$ radiocollars manufactured by us and were released the same day (23 January 1982) on the capture site. From the day of capture to the beginning of February, the diurnal resting places of the animals were determined by radio location from a mobile receiver unit equipped with dual 4-element Yagi antennas, a null-peak system and an AVM LA 12 receiver. They always remained within the geographic limits of the reserve, no dispersion occurring (Pépin and Cargnelutti 1985).

Then, as described by Spitz and Janeau (1990) for the wild boar, the radio locations of hares were obtained by triangulation of simultaneous (synchronized by VHF transceivers) radio bearings from two mobile receiver units, because the location error caused by animal movement can only be eliminated by taking simultaneous bearings (Schmutz and White 1990). They were monitored at a rate of three times per hour from 08.00 to 15.59 Greenwich Mean Time (GMT), i.e. during daylight period, and six times per hour during the remainder. As indicated by Harris et al. (1990) and Reynolds and Laundre' (1990) such short intervals between radio fixes over a set time period provide at the very least a rough approximation of an animal's travel route. In weeks 6 (from 3 to 5 February), 8 (from 17 to 19 February) and 10 (from 3 to $5 \mathrm{March}$ ), data were recorded at such rates for a total of about 42 hours, from 14.00 or 16.00 on day 1 to 08.59 on day 3 . Then, in week 12 , we recorded data from 13.00 on 17 March to 08.59 on the following day.

\section{Data analysis}

The usual working distance from radiotracked hares $(<500 \mathrm{~m})$, and tests with reference transmitters placed at known locations within this distance indicated that radio locations were accurate within a radius of $50 \mathrm{~m}$ or less. Considering this sampling error (Springer 1979), a map of the area was overlaid within a $50 \times 50 \mathrm{~m}$ grid, and, as proposed by Bideau et al. (1983) for the roe deer, the 
locations of all the fixes were arbitrarily reported as being at the centre of the grid squares because two location points falling within a given cell of the grid cannot be accurately distinguished from each other.

The general activity pattern of the hares during the study period was deduced from consecutive radio locations obtained on each individual both from the estimated distance travelled and from the recorded changes of squares. However, as recently reviewed by Saltz (1994), taking into account that the precision of estimated locations is a consequence of the distance from the receiving sites, and the intersection angle of the triangulated bearings, both the doubtful data concerning locations of hares $>500 \mathrm{~m}$ from a receiver unit or obtained with angles $<45^{\circ}$ or $>135^{\circ}$ were excluded of the first analysis. In the latter case, a hare was considered to be active between 2 consecutive radio bearings when a change of location was recorded. In order to average the daily activity pattern of hares during winter, the accurate data from these 2 approaches were separately pooled during each 4 -h interval (starting with 00.00-03.59), and were compared using the Spearman rank correlation coefficient $(r \mathrm{~s})$. Then, the frequency of bearings corresponding with activity during the night (from 18.00 to 07.59 ) and during daylight was compared using the $\chi^{2}$-test. We also used $\chi^{2}$-test to compare the rate of activity of each individual hare from their respective recorded changes of squares, and in each case we performed Haberman's (1973) procedure to identify the cells of the contingency table that contributed significantly $(p<0.05)$ to the heterogeneity of the data.

The times of onset and cessation of locomotor activity of radiotracked hares in relation to sunset and sunrise were estimated on the assumptions that a studied animal was active near sunset, when $>2$ successive changes in radio locations were recorded, and inactive near sunrise, when it was found in the same square for $>2$ consecutive radio fixes. Average daylight duration was $9.5 \mathrm{~h}$ on week 6 (from 07.20 to 16.50 ), $10.2 \mathrm{~h}$ on week 8 (from 07.00 to 17.10 ), $11.2 \mathrm{~h}$ on week 10 (from 06.30 to 17.40 ), and $12.0 \mathrm{~h}$ on week 12 (from 06.00 to 18.00 ).

Then, we predicted that the movement of the hares should differ firstly among individuals within a given period in spite of the fact that they are submitted to similar environmental conditions, and secondly for the same individual because of differences in external stimuli, previous decisions and/or motivational state. Herein, we compare the activity patterns of hares over 2 consecutive night cycles, and also the nocturnal activity of a particular animal over several cycles, when sufficient data were available; such longitudinal measurements providing information about the process of behavioural change, as well as its outcome (Martin and Kraemer 1987).

\section{Results}

\section{Activity pattern as deduced from changes in radio location}

The average daily activity pattern of the hares determined from the accurate radiotracking data showed a clear nocturnal high level of activity (Fig. 1). A strong

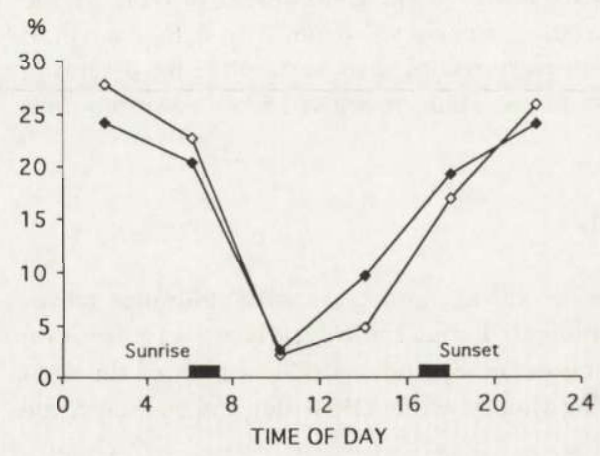

Fig. 1. Average daily activity pattern of four European hares in Le Faget area during winter 1982 Patterns of locomotor activity are represented for each 4-hr interval as a percentage of distance travelled (white rectangles) and percentage of active individuals (black rectangles). 
correlation existed between the percentage of daily distance travelled and the percentage of daily active hares recorded in each equivalent time period as interpreted from any changes in radio locations $(r \mathrm{~S}=1, p<0.001)$.

On average, hares were active for $47.2 \%$ of the bearings made from 18.00 to $07.59(n=1198)$, compared to only $15.1 \%$ from 08.00 to $17.59\left(n=278, \chi^{2}=95.75\right.$, $\mathrm{df}=1, p<0.001$ ). As reported in Table 1 , the average rate of active animals progressively increased from $08.00-11.59(6.7 \%)$ to $20.00-23.59$ (51.9\%).

However, when comparing individual data, we found that some significant variations occurred for all the hares, at least during part of the time of day (Table 1). A higher rate of activity was particularly recorded for male No 1 , both between 12.00 and 15.59 (corresponding to a smaller rate for female No $4, p=0.0012$ ) and

Table 1. Level of activity (\%) for individual adult brown hares according to the time of day, as estimated on the basis of changes in radio location. $n$-sample size. * Cells of the contingency table of the $\chi^{2}$-test $(\mathrm{df}=3)$ that contributed significantly to the heterogeneity of data in each 4-hr interval.

\begin{tabular}{|c|c|c|c|c|c|c|c|c|c|c|c|c|}
\hline \multirow{3}{*}{ Animal } & \multicolumn{12}{|c|}{ Time of day (4-hr intervals) } \\
\hline & \multicolumn{2}{|c|}{$00.00-03.59$} & \multicolumn{2}{|c|}{$04.00-07.59$} & \multicolumn{2}{|c|}{$08.00-11.59$} & \multicolumn{2}{|c|}{$12.00-15.59$} & \multicolumn{2}{|c|}{$16.00-19.59$} & \multicolumn{2}{|c|}{$20.00-23.59$} \\
\hline & $n$ & $\%$ & $n$ & $\%$ & $n$ & $\%$ & $n$ & $\%$ & $n$ & $\%$ & $n$ & $\%$ \\
\hline Male No 1 & 20 & 60.0 & 30 & $76.7^{*}$ & 29 & 3.4 & 32 & $37.5^{*}$ & 52 & 46.1 & 23 & 47.8 \\
\hline Female No 2 & 44 & $75.0^{*}$ & 36 & 47.2 & 12 & 8.3 & 16 & 12.5 & 32 & 34.3 & 41 & 61.0 \\
\hline Male No 3 & 145 & $44.8^{*}$ & 131 & $34.3^{*}$ & 36 & 2.8 & 76 & 26.3 & 99 & 43.7 & 153 & 47.1 \\
\hline Female No 4 & 94 & 51.1 & 74 & 45.9 & 28 & 14.3 & 49 & $4.1^{*}$ & 129 & 41.9 & 95 & 56.8 \\
\hline$\Sigma$ & 303 & 52.1 & 271 & 43.9 & 105 & 6.7 & 173 & 20.8 & 312 & 40.3 & 312 & 51.9 \\
\hline$\chi^{2}$ & \multicolumn{2}{|c|}{12.860} & \multicolumn{2}{|c|}{18.215} & \multicolumn{2}{|c|}{4.024} & \multicolumn{2}{|c|}{15.799} & \multicolumn{2}{|c|}{2.487} & \multicolumn{2}{|c|}{3.872} \\
\hline$p$ & \multicolumn{2}{|c|}{0.0049} & \multicolumn{2}{|c|}{0.0004} & \multicolumn{2}{|c|}{0.2589} & \multicolumn{2}{|c|}{0.0012} & \multicolumn{2}{|c|}{0.4777} & \multicolumn{2}{|c|}{0.2757} \\
\hline
\end{tabular}

between 04.00 and 07.59 (corresponding to a smaller rate for male No $3, p=$ 0.0004 ). We also found that male No 3 already had a low level of activity during the previous $4 \mathrm{~h}$ period (between 00.00 and 03.59), while those of female No 2 peaked (33 changes in location out of 44 cases, $p=0.0049$ ).

Daily activity period according to the time of sunset and sunrise

From the individual data reported in Table 2, we estimated that the average daily activity of hares started 23 min after sunset $(\mathrm{SD}=46, n=17$, range $=110$ min before and after sunset), and ended 14 min before sunrise (SD $=42, n=16$, range $=60$ min before and after sunrise). By comparing the animals sampled, we found that hare No 1 (adult male) spent more time in activity than any of the other 3 ( $15.5 \mathrm{~h}$ vs $12.9 \mathrm{~h}$ on average, $\mathrm{SD}=14 \mathrm{vs} 0.9, n=4 \mathrm{vs} 12$ ), generally starting earlier and ending later (Table 2). 


\section{Inter-individual variations in distance travelled during a given period}

The mean daily distance travelled by animals over $24 \mathrm{~h}$ was $3.91 \mathrm{~km}(n=12$, $\mathrm{SD}=1.46$, range $=1.39-6.02$; Table 2 ) .

Detailed analysis of data recorded during the first sampling period (week 6) for 3 different animals (not enough accurate data for male No 1) is given in Fig. 2. As previously described for the general activity pattern, we first observed that

Table 2. Onset and cessation of activity for individual adult hares as estimated from the assumption that activity started (near sunset) when $>2$ changes in radio location were successively recorded, and ended (near sunrise) when $>2$ radio locations without changes were recorded. $\Delta$ - daily duration of activity, D - total distance travelled.

\begin{tabular}{|c|c|c|c|c|c|c|c|c|c|}
\hline \multirow{2}{*}{ Week } & \multirow{2}{*}{ Animal } & \multicolumn{4}{|c|}{ Days 1-2 } & \multicolumn{4}{|c|}{ Days 2-3 } \\
\hline & & Onset & End & $\Delta(\mathrm{h})$ & $\mathrm{D}(\mathrm{m})$ & Onset & End & $\Delta(\mathrm{h})$ & $\mathrm{D}(\mathrm{m})$ \\
\hline \multirow[t]{4}{*}{6} & Male No 1 & 17.00 & 08.20 & 17.3 & - & 17.10 & 07.40 & 17.5 & - \\
\hline & Female No 2 & 17.20 & 06.30 & 13.2 & 5400 & 17.30 & 07.20 & 13.8 & 4990 \\
\hline & Male No 3 & 17.00 & 06.30 & 13.5 & 5965 & 18.10 & 06.30 & 12.3 & 2475 \\
\hline & Female No 4 & 16.30 & 06.30 & 14.0 & 4480 & 18.40 & 06.30 & 11.8 & 4315 \\
\hline \multirow[t]{3}{*}{8} & Male No 1 & 15.20 & 07.40 & 16.3 & - & 17.00 & 06.50 & 13.8 & - \\
\hline & Male No 3 & 17.30 & 06.00 & 12.5 & 2630 & 17.40 & 06.20 & 12.7 & 3035 \\
\hline & Female No 4 & 18.30 & 06.10 & 11.7 & - & 17.40 & 08.00 & 14.3 & - \\
\hline 10 & Male No 3 & 18.20 & 06.10 & 11.8 & 2550 & 18.00 & 07.00 & 13.0 & 5305 \\
\hline
\end{tabular}

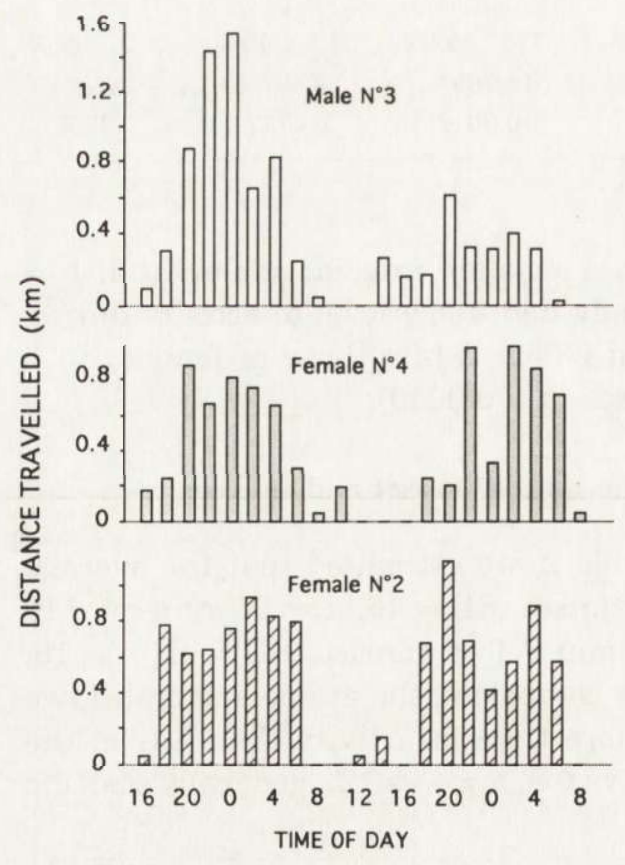

Fig. 2. Locomotor activity pattern of three adult European hares in Le Faget area during 3-5 February 1982 (week 6) calculated for every 2 -hr interval from pooled distance travelled as recorded 3 times per hour from 08.00 to 15.59 or 6 times per hour for the remainder. Male No 3 at the top, female No 4 in the midlle, and female No 2 at the bottom. 
the diurnal movements of animals recorded during daylight on February 4th were rather low ( $<500 \mathrm{~m}$ from 08.00 to 17.59$)$ with respect to their high nocturnal activity. For both adult females, the total distance travelled from 18.00 to 07.59 was about the same during the two consecutive nights (respectively 5.61 and 5.13 $\mathrm{km}$ for No 2, and 4.30 and $4.35 \mathrm{~km}$ for No 4 ). However, the distance travelled over $2 \mathrm{~h}$ remained more stable for No 2 than for No 4 (coefficients of variation $=14$ and 34 vs 40 and 57). In the case of adult male No 3, a high peak of locomotor activity was recorded from 22.00 to 01.59 during the first night ( $>1 \mathrm{~km}$ in each 2-hr interval) that consequently produced a large coefficient of variation (60). During the second night though, a drastic reduction of activity occurred (from 6.02 to $2.62 \mathrm{~km}$, i.e. a decrease of about $56 \%$; see Table 2 and Fig. 2).

\section{Intra-individual variations in distance travelled during various nights}

As mentioned above, comparison between consecutive nocturnal locomotor activity cycles of male hare No 3 showed that some significant changes may be detected from one night to the following (see A vs B, or E vs F in Fig. 3), both overall (activity more than 2 times lower or higher) and in the mean distance travelled during every 2 -hr interval $(p<0.01)$. Moreover, even if about the same global extent of nocturnal movements exists during several cycles (B, C, D, E and $\mathrm{G}$ in Fig. 3), variations in 2-h activity level could be detected during the course of a given night: for instance Fig. 3 shows that no moves were recorded from 00.00 to 01.59 during night $\mathrm{D}$ and that an unusually intense locomotor activity occurred from 04.00 to 05.59 during night C. During week 8 , the distance travelled by female No 4 was very short $(1.39 \mathrm{~km})$ on days $1-2$, but was again at a rather average level $(3.69 \mathrm{~km})$ on days $2-3$, compared to the previous estimations made during week 6 (Table 2).

Fig. 3. Cumulative nocturnal distance travelled from 18.00 to 08.00 by male No 3 in Le Faget area during various nights in winter 1982 calculated for every 2 -hr interval from poled data recorded 6 times per hour. A refers to 3-4 February, B to 4-5 February, C to 17-18 February, D to 18-19 February, E to 3-4 March, F to 4-5 March, and G to 17-18 March.

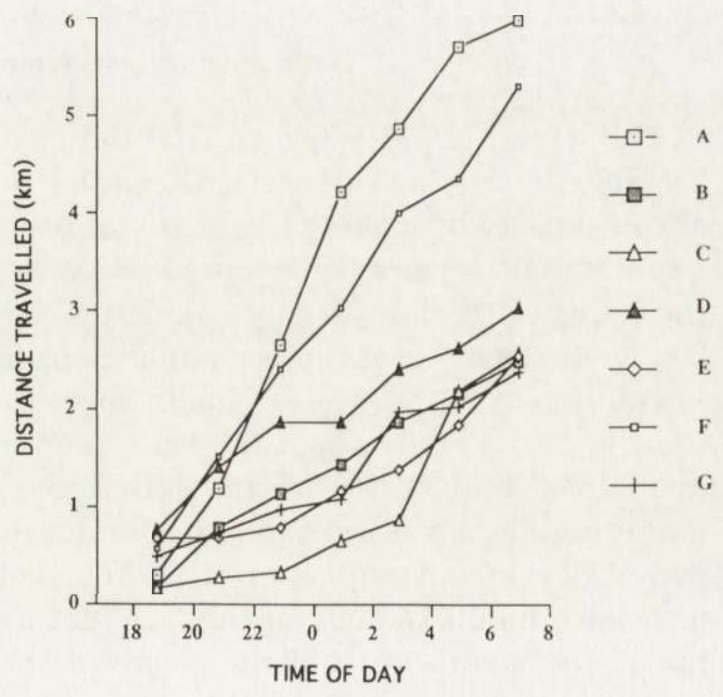




\section{Discussion}

Daily activity pattern and length of the light phase

Direct field observation of anonymous animals, mostly possible during the light phase, has permitted European hares to be referred to as typically nocturnal herbivores, the diurnal period of rest being only interrupted by short intervals devoted to grooming, moving or contacting other individuals (Schneider 1977, Flux 1981, Homolka 1986). However, the boundaries between the periods of rest and activity varied seasonally, depending on the length of the light phase: for instance, Homolka (1986) found that in summer there was a marked decrease in activity of hares lasting for only 4 hours between 11.00 and 15.00 while in winter the activity of the hares began approximately one hour before sunset (at 17.00) and ended round 08.00 in the morning. Moreover, as pointed out by Matuszewski (1981), at the end of winter and early spring, the beginning and the end of circadian movements of hares, from the edge of a forest to fields during evening hours and back to the forest in the morning, did not depend exactly on the time of sunset of sunrise, the intensity of the latter being almost twice as great.

Although the present investigation was based on the monitoring of daily movements of radiotracked hares during winter, and consequently cannot distinguish between different kinds of activity, we found that the average daily activity pattern of animals was globally in accordance with the two findings reported above i.e. a change from a low level of activity in the morning (08.00-11.59) to a high level during the night, and a progressive increase in the intensity of movements of hares in the evening contrasting with a more stronger decrease in the morning. From data obtained on a radiocollared female snowshoe hare, Mech et al. (1966) also found greater variations in the relationship between sunset and the onset of activity than in sunrise and the cessation of activity.

\section{Daily activity pattern and social factors}

Schneider (1977) indicated that the daytime activity of hares increased when the density was high in a given area, hares responding to a substantial thinning of this density by moving their activity peaks into darkness. Similarly, comparing two different sectors, Homolka (1986) also reported that the foraging activity of the hares in the low density population area had sharper limits, and that social behaviour firstly took up a smaller percentage of time than in an area of high population density, and secondly increased in connection with the onset of breeding. In a study about the behaviour of hare does and leverets. Broekhuisen and Maaskamp (1980) observed that the time of arrival of the young at the gathering place was, on average, 45 minutes after sunset (range 10-70 min after sunset), i.e. about a quarter of an hour before they were observed to be nursed once each night. In spite of the fact that the time of nursing was not completely fixed, and significant individual variations were recorded, it seems that in all 
cases, before they started foraging, the lactating females spent the first part of their nocturnal locomotor activity moving to their leverets to nurse them.

As mentioned above, the density of the hare population at our study site was rather low, even in the game reserve area. We know that, at the end of January, the captured adult females were not pregnant. But later, when their locomotor activity was recorded, we were unable to know if they had given birth to leverets, and consequently if they were nursing. However, the use of the radio-tracking technique permitted us to separately estimate the average rate of activity of each hare during precise time intervals (every $4-\mathrm{hr}$ ), and to detect significant variations among animals during daytime (from 12.00 to 15.59) or during the night (between 00.00 and 07.59; Table 1). Moreover, we found that the adult male No 1 spent more time in activity than the other adult male and the two females, generally both starting earlier and ending later. This variation between the 2 males seems to corroborate the observations made by Mech et al. (1966) among male cottontail rabbits. We suggest that such variation of the circadian activity in males could be based on a hierarchical ranking order amongst males living together. Indeed, from observations conducted both on free-living and captive hares, Schneider (1981) mentioned that low rank animals were much more active than other individuals in higher social positions.

\section{Individual locomotor activity and other factors}

Taking advantage of the discovery of a single track of the jackrabbit Lepus californicus in snow, Tenaille (1941) minutely described the strategy used by the animal when entering a resting place: the perfectly equidistant footprints were, in fact, alternated on some distinct parts of the snowtrack, the last footprint at the end of each junction being in a wrong direction; access to the previously selected resting place was made by means of a perpendicular 4-5 meters jump from the snowtrack. Also called "backtracking", this complicated behavioural strategy, only detectable by visual observation, is also used by the European hare in snowfree situations: giving the diagrams of tracks of the same hare on 4 consecutive mornings, Flux (1981) noted that both the complexity and direction of backtracking varied from day to day, even though similar times of arrival at the resting place were recorded. Consequently, although choosing one option over another is influenced by various factors, such decision making could be used to confuse predators hunting by olfaction.

So precise data on the movements of radiotracked hares can not be obtain be the technique used in the present study. But, analysing the distance travelled every $2 \mathrm{~h}$ by individual hares for which we have enough accurate data (see the precision of estimated locations given in the data analysis section), we evaluated that the average daily movements of hares ranged between 1.39 and $6.02 \mathrm{~km}$. On the other hand, recording the locomotor activity of individuals simultaneously (i.e. in similar environmental conditions), we noted that some hares behave in a 
similar way during two consecutive nights (male No 3 in week 8, or female No 4 in week 4), while the same animals behave differently on other occassions (male No 3 in weeks 6 and 10, and female No 4 in week 8). The present results show that the patterns of locomotor activity of hares may unpredictably change at the individual level, possibly in order to also confuse the predators.

Acknowledgements: Financial support was provided by the Office National de la Chasse (National Game Agency), and field assistance by G. Janeau, E. Lécrivain, J. C. Ricci, F. Spitz and G. Valet. We thank P. Winterton for improving the English of this article, and the referees for the critical reading and valuable comments made on the manuscript.

\section{References}

Anderson B. and Pelton M. R. 1976. Movements, home range, and cover use: factors affecting the susceptibility of cottontails to hunting. Southeastern Assoc. Game and Fish Commissioners. Thirtieth Annual Conf.: 525-535.

Aschoff J. 1966. Circadian activity pattern with two peaks. Ecology 47: 657-662.

Bideau E., Vincent J. P., Quéré J. P. and Angibault J. M. 1983. Occupation de l'espace chez le chevreuil (Capreolus capreolus L., 1789). I. Cas des mâles. Acta OEcol., OEcol. Applic. 4: 163-184.

Broekhuisen S. and Maaskamp F. 1980. Behaviour of does and leverets of the European hare (Lepus europaeus) whilst nursing. J. Zool., Lond. 191: 487-501.

Cederlund G. and Lemnell P. A. 1980. Activity recording of radio-tagged animals. Biotelemetry Patient Monitg 7: 206-214.

Cochran W. W. and Lord R. D., Jr 1963. A radio-tracking system for wild animals. J. Wildl. Manage. 27: 9-24.

Cochran W. W., Warner D. W., Tester J. R. and Kuechle V. B. 1965. Automatic radio-tracking system for monitoring animal movements. BioScience 15: 98-100.

Figala J., Tester J. and Seim G. 1984. Analysis of the circadian rhythm of a snowshoe hare (Lepus americanus, Lagomorpha) from telemetry data. Věst. Čs. Spol. zool. 48: 14-23.

Flux J. E. C. 1981. Field observations of behaviour in the genus Lepus. [In: Proceedings of the data World Lagomorph Conference. K. Myers and C. D. McInnes, eds]. Gland 1981: 377-394.

Haberman S. J. 1973. The analysis of residuals in cross-classified tables. Biometrics 29: 205-220.

Harris S., Cresswell W. J., Forde P. G., Trewhella W. J., Woollard T. and Wray S. 1990. Home-range analysis using radio-tracking data - a review of problems and techniques particularly as applied to the study of mammals. Mammal Rev. 20: 97-123.

Homolka M. 1986. Daily activity pattern of the European hare (Lepus europaeus). Folia Zool. 35: 33-42.

Kucera J. 1981. Intraindividual and interindividual differences of beahviour in hare (Lepus europaeus Pallas, 1778) and rabbit (Oryctolagus cuniculus Linnaeus, 1758). Folia Venatoria 10-11: 237-249. [In Czech with English summary]

Lemmel P. A. and Lindlölf B. 1981. Diurnal and seasonal activity pattern in the mountain hare. [In: Proceedings of the World Lagomorph Conference. K. Myers and C. D. McInnes, eds]. Gland 1981: 349-356.

Łomnicki A. 1988. Population ecology of individuals. Monographs in population biology 25. Princeton Univ. Press, Princeton: 1-224.

Martin P. and Kraemer H. C. 1987. Individual differences in behaviour and their statistical consequences. Anim. Behav. 35: 1366-1375.

Matuszewski G. 1981. Circadian activity of European hares in spring, on the Kampinos forest border. [In: Proocedings of the World Lagomorph Conference. K. Myers and C. D. McInnes, eds]. Gland 1981: 357-365. 
McNamara J. M. and Houston A. I. 1986. The common currency for behavioural decisions. Am. Nat. 127: $358-378$.

Mech L. D., Heezen K. L. and Siniff D. B. 1966. Onset and cessation of activity in cootonail rabbits and snowshoe hares in relation to sunset and sunrise. Anim. Behav. 14: 410-413.

Nielsen E. T. 1984. Relation of behavioural activity rhythms to the changes of day and night. A revision of views. Behaviour 89: 147-173.

Pépin D. and Birkan M. 1981. Comparative total-and-strip census estimates of hares and partridges. Acta OEcol., OEcol. Applic. 2: 151-160.

Pépin D. and Cargnelutti B. 1985. Dispersion et cantonnement de lièvres de repeuplement (Lepus europaeus). Biol. Behav. 10: 353-365.

Reynolds T. D. and Laundre' J. W. 1990. Time intervals for estimating pronghorn and coyote home ranges and daily movements. J. Wildl. Manage. 54: 316-322.

Ricci J. C. 1983. Suivi d'un lâcher de lièvres d'importation (Lepus europaeus Pallas) au moyen de la radiotélémétrie: mortalité, dispersion et utilisation de l'espace. Acta OEcol., OEcol. Applic. 4: $31-46$.

Rongstad O. and Tester J. 1971. Behavior and maternal relations of young snowshoe hares. J. Wildl. Manage. 35: 338-346.

Saltz D. 1994. Reporting error measures in radio location by triangulation: a review. J. Wildl. Manage. 58: 181-184.

Schneider E. 1977. Verhaltensstudien am Feldhasen (Lepus europaeus Pallas). Beitr. Jagd- und Wildforschung 10: 277-288.

Schneider E. 1981. Studies on the social behaviour of the brown hare. [In: Proceedings of the World Lagomorph Conference. K. Myers and C. D. McInnes, eds]. Gland 1981: 340-348.

Schmutz J. A. and White G. C. 1990. Error in telemetry studies: effects of animal movement on triangulation. J. Wildl. Manage. 54: 506-510.

Slater P. J. 1981. Individual differences in animal behavior. [In: Perspectives in ethology. Vol. 4. P. P. G. Bateson and P. H. Klopfer, eds]. Plenum Press, New York: 35-49.

Spitz F. and Janeau G. 1990. Spatial strategies: an attempt to classify daily movements of wild boar. Acta theriol. 35: 129-149.

Springer J. T. 1979. Some sources of bias and sampling error in radio triangulation. J. Wildl. Manage. 43: 926-935.

Tenaille J. 1941. Intelligence ou instinct chez le lièvre. Mammalia 5: 101-102.

Received 19 July 1993, accepted 5 August 1994. 